\title{
CARDIOVASCULAR INVOLVEMENT IN TROPICAL EOSINOPHILIA
}

\author{
BY \\ RUSTOM JAL VAKIL \\ From the Cardiac Departments, King Edward Memorial Hospital, and Bombay Hospital, Bombay, India
}

Received December 7, 1960

First introduced to the medical profession by Frimont-Möller and Barton (1940) as a "pseudotuberculous condition associated with eosinophilia" with a clinical report of 175 cases, the condition popularly known today as "tropical eosinophilia" (Weingarten, 1943) offers many points of interest. Its high incidence in certain geographical regions, particularly along the coastal belts of India, contrasted with its rarity in the Western hemisphere; its recent recognition despite a high prevalence; its obscure ætiology, pathogenesis, and epidemiology, and its prompt response to arsenicals and diethylcarbamazine; and the preponderant involvement of the respiratory system; all these are some of the unexplained problems that offer a challenge to the enquiring investigator.

Also referred to in the past as "pulmonary eosinophilosis," "benign eosinophilia with pulmonary shadows," "tropical pulmonary eosinophilia," "eosinophil lungs," and "tropical eosinophilemia," the syndrome of tropical eosinophilia, with its characteristically high eosinophilic leucocyte count, fever, and pulmonary symptoms, has been variously attributed to allergy, spirochætosis, filariasis, virus infection, and infestation with the acarus. After the recent isolation of the Wucheria Malayi from the lymph nodes of a few patients by Van der Sar (1945), and the investigations of Danaraj et al. (1957) and Gault and Gebba (1957), the focus of interest has suddenly shifted to the filarial theory of origin.

Apart from a solitary post-mortem report by Vishwanathan $(1947,1948)$, there are no pathological data to establish the exact position of the disease in the large group of eosinophilic disorders. Its relationship, for instance, to Loeffler's syndrome (1932), an eosinophilic disorder of temperate climates associated with pulmonary infiltration, and to the "disseminated eosinophilic collaginosis" of Bousser (1957), with eosinophilia and a variety of systemic manifestations, has not as yet been clarified.

Although associated with a host of respiratory symptoms and signs, a febrile course, and massive eosinophilia, tropical eosinophilia responds promptly and effectively to arsenicals and diethylcarbamazine, the therapeutic response being at times nothing short of dramatic. Although interest has been recently focussed by many authors on the so-called aberrant, atypical, or extra-pulmonary manifestations of the disease, including involvement of the gastro-intestinal system (Chaudhuri, 1956), lymphadenopathy, pleurisy (Joseph, 1946), nephritis (Meyers and Kouwenar, 1939), and skin lesions, little or no attention has been paid to the cardiovascular manifestations of the disease. Earlier papers on the subject give the impression that involvement of the cardiovascular system in tropical eosinophilia was rare or non-existent. In view of the contrary experience of the author and the paucity of existing data on the subject the following clinical investigation has been made.

\section{MATERIAL AND METHOD}

The present study consists of a detailed examination of the cardiovascular system, clinically and electrocardiographically, in one hundred hæmatologically proven cases of tropical eosinophilia. 
They were of all degrees of severity, ranging from mild and afebrile to intensely severe forms of the disease, with eosinophil percentage counts ranging from 25 to 80 per cent of the total white cells. All patients were subjected to serial electrocardiography, employing 12-leads, during and after the acute phase of the illness. In all, 208 tracings were analysed and a detailed study made for evidence of arrhythmias and other abnormalities. Of the 100 patients, 62 were male and 38 female, with an age range of from 9 to 66 years and average age of 28 years.

\section{OBSERVATIONS}

Clinical Findings. Certain symptoms suggestive of heart disease, such as dyspnoa and cough, are proverbially difficult to evaluate in a disease like tropical eosinophilia, in which there is preponderant involvement of the respiratory system. Nevertheless, the presence of exertional or postural dyspnœa (orthopnœa), and nocturnal attacks of paroxysmal dyspnœa, especially when associated with abnormal physical findings over the præcordial area and signs of cardiac decompensation, such as engorged neck-veins, ankle œdema, and painful enlargement of the liver, should suggest the possibility of cardiac involvement.

In the present series, vague præcordial aches and pains were complained of by at least 20 per cent of patients, but typically anginal cardiac pain was only encountered thrice. In one patient (Case 6), the anginal pain was severe and prolonged enough to warrant a diagnosis of acute coronary insufficiency, later to be corroborated by electrocardiographic evidence of myocardial ischæmia.

The physical examination of the heart revealed relatively few physical signs. Systolic murmurs (Grade I-III) were heard transitorily, over the pulmonary or mitral area or over both regions, in 7 patients; accentuation of the pulmonary component of the second sound was present in 36 instances and gallop rhythm in only 3 . Signs of congestive heart failure, such as tender enlargement of the liver, gravitational œdema, and distended neck veins, were observed in six patients.

Joint pains with swelling and redness were observed in 4 patients, generalized lymphadenopathy in 7, hepatomegaly with no other signs of congestive heart failure in 8 , and splenomegaly in 3 patients. Hyperpyrexia, pleurisy, gastrointestinal involvement, and peripheral failure, reported as rare complications by other authors, were not seen at all in the present series.

TABLE I

EleCtrocardiographIC Findings IN 100 CASES OF Tropical EOSINOPHILIA

\begin{tabular}{|c|c|c|c|c|c|c|}
\hline \multicolumn{6}{|c|}{ Nature of abnormality } & Number of cases \\
\hline \multicolumn{7}{|c|}{ Disturbances of Rate and Rhythm: } \\
\hline Sinus tachycardia & .. & .. & .. & .. & & 42 \\
\hline Sinus bradycardia & . & & .. & .. & .. & 3 \\
\hline Atrial premature systoles & & & .. & .. & .. & 2 \\
\hline Ventricular premature sy & & .. & .. & .. & $\ddot{.}$ & 6 \\
\hline Supraventricular paroxys & tachycardia & & .. & .. & & 1 \\
\hline \multicolumn{7}{|c|}{$\begin{array}{l}\text { Disturbances of Conduction: } \\
\text { Ding }\end{array}$} \\
\hline First degree A-V heart $\mathrm{b}$ & & $\cdots$ & $\cdot$ & .. & . & 2 \\
\hline Incomplete right bundle- & ach block & & & .. & .. & 3 \\
\hline \multicolumn{7}{|c|}{ Relative Ventricular Preponderance and Position of Heart: } \\
\hline Right axis deviation . . & .. $\quad .$. & .. & .. & .. & . & 10 \\
\hline Right ventricular strain & .. & . & . & .. & .. & 4 \\
\hline Left ventricular strain & & & .. & .. & & 2 \\
\hline \multirow{2}{*}{\multicolumn{7}{|c|}{ Abnormalities of Ventricular or Atrial Complexes: $\cdots$}} \\
\hline \multicolumn{3}{|c|}{ Decreased amplitude of $\mathrm{QRS}$ (under $5 \mathrm{~mm}$. in limb leads) } & & & .. & 2 \\
\hline \multirow{2}{*}{\multicolumn{3}{|c|}{ Slurring or notching of QRS ..... }} & .. & .. & .. & 5 \\
\hline & & & .. & .. & .. & 4 \\
\hline \multicolumn{3}{|c|}{ Increased amplitude and/or duration of $\mathbf{P}$ wave } & .. & .. & .. & 2 \\
\hline \multicolumn{2}{|c|}{ Diminished amplitude and/or duration of $\mathbf{P}$ wave } & & .. & .. & .. & 8 \\
\hline \multicolumn{3}{|c|}{ Non-specific abnormalities of $\mathrm{S}-\mathrm{T}$ segments } & .. & .. & .. & 12 \\
\hline
\end{tabular}


All the patients made uneventful recoveries from the malady itself. Dyspnœa of effort continued for two to eight weeks after subsidence of fever in six of the cases. Apart from one patient (Case 6) who showed evidence of subendocardial infarction and later died with transmural infarction, there were no fatalities in the entire group. It was significant that cardiovascular symptoms and signs, whenever present, bore no relationship to the degree or duration of pyrexia, intensity of respiratory involvement, or level of eosinophilia, but were observed mainly in those patients in whom specific therapy was greatly delayed or when there was pre-existing heart disease.

Electrocardiographic Findings. Significant changes in the electrocardiogram (exclusive of sinus tachycardia) were observed during the acute illness in 37 of the 100 patients studied (Table I). On the whole, the cardiographic abnormalities were mild, infrequent, and transient, with the exception of a few isolated instances in which the patterns gave reason for concern.

\section{ILlustrative CASE RePORTS}

The following selected case reports serve to illustrate some of the types of cardiovascular involvement that may occur in tropical eosinophilia. By no means common or representative of the disease as a whole, they should be regarded as atypical or exceptional manifestations.

Case 1. A 30-year-old man complained of low-grade fever of 16 days' duration with severe, hacking cough, dyspnœa, and intermittent præcordial ache. In spite of antibiotics, antipyretics, and cough syrups, the dyspnœa and cough were proving increasingly troublesome. Clinical examination revealed a thin man with flushed face, "wheezy" respiration, mild pharyngitis, and rhonchi all over the chest. There was a rapid cardiac rate of 110 a minute and a grade II systolic murmur over the pulmonary area. The blood pressure was 120/80. The liver was slightly enlarged and tender. The total WBC count was 16,400 with 54 per cent eosinophils. The urine and stools were normal.

Electrocardiograms taken on the second day of observation showed low voltage of $T$ waves in the limb leads and in leads V4 to V6, with non-specific depression of ST-T segments in the same leads (Fig. 1A).

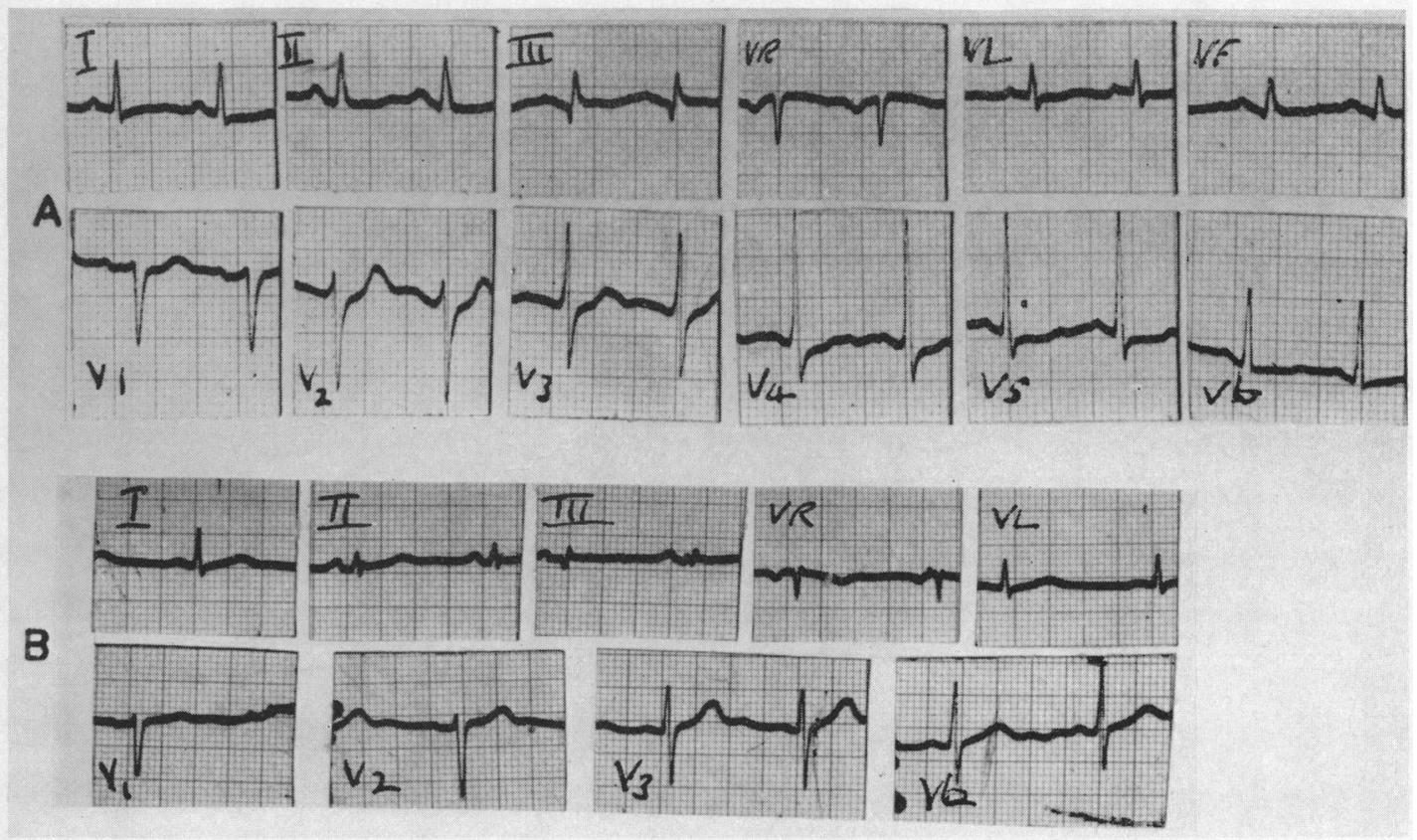

Fig. 1.-Case 1. Electrocardiogram showing (A) low voltage of $\mathrm{T}$ waves and S-T segment depression; and (B) correction of these abnormalities 14 days later. 
By treatment with two tablets of hetrazan four times a day the patient became afebrile on the fourth day while the eosinophilia, hepatomegaly, and non-specific ST-T abnormalities disappeared by the end of the second week (Fig. 1B). Slight dyspnœa of effort, general loss of strength and nocturnal cough persisted for at least a month after the start of treatment.

Comment. Cardiovascular involvement in this patient with tropical eosinophilia was suggested by the appearance of transitory electrocardiographic abnormalities in conjunction with præcordial ache, dyspnœa of effort, and nocturnal cough.

Case 2. A 19-year-old student became ill rather suddenly with cough, aching in the body, high fever, wheezy breathing, and dyspnœa. Antibiotics, antipyretics, and diaphoretics were given for almost two weeks without avail. On the twelfth day of fever $\left(99^{\circ}\right.$ and $\left.130^{\circ} \mathrm{F}\right)$, she suddenly developed a sharp, lancinating pain over the præcordium, with exacerbation of fever and dyspnœa.

On examination, the thin and pale young woman was in obvious distress, with pain located mainly in the third and fourth left interspaces. Although the heart sounds were normal and no murmurs were detected, a superficial, scratchy to-and-fro pericardial friction rub became audible over the mid-præcordial areas, it was increased in intensity by pressure on the chest-piece of the stethoscope. Rhonchi and moist sounds were heard over both sides of the chest. Signs of heart failure were not present. The electrocardiogram

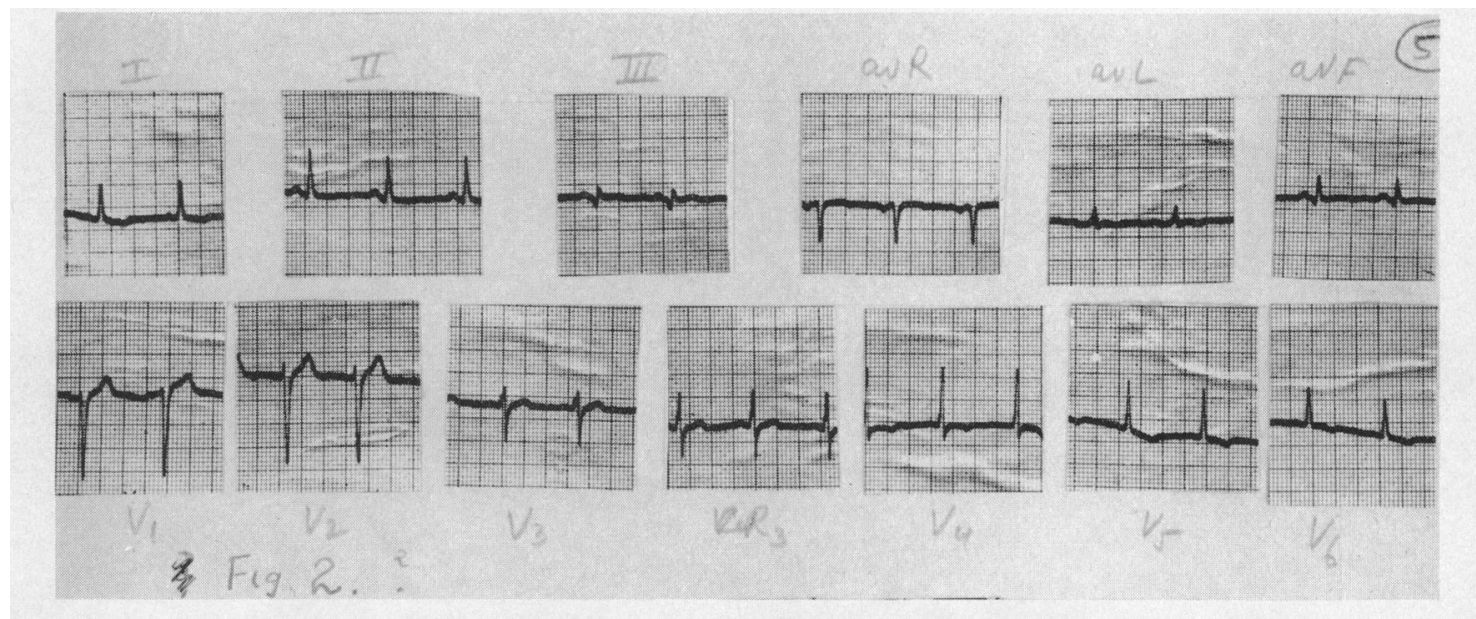

FIG. 2.-Case 2. Electrocardiogram showing sinus tachycardia, shallow inversions of T waves and mild S-T segment depression.

taken within 16 hours of onset of pain (Fig. 2) showed sinus tachycardia with shallow inversions of T waves and mild S-T segment depressions in leads I, II, aVL, and V4 to V6. In conjunction with the physical signs the cardiogram was consistent with a diagnosis of acute dry pericarditis.

The blood count showed 15,600 WBC, with 46 per cent eosinophils. The urine and stools were normal.

After two injections of acetylarsan $(3 \mathrm{ml}$.), at an interval of five days, the patient made an uneventful recovery. The pericardial friction and fever disappeared within three days of beginning treatment; the eosinophil count regressed to 12 per cent within a week, and the cardiogram reverted to normal within three weeks. Subsequent follow-up of the patient revealed no residual symptoms or signs.

Comment. In this patient the signs and the abnormal cardiogram appearing suddenly at the height of infection led to a diagnosis of acute dry pericarditis. The uneventful recovery after acetylarsan injections endorsed this diagnosis. Inflammation of the pericardium as a complication of tropical eosinophilia has not, I believe, hitherto been recorded.

Case 3. A 26-year-old woman, who gave a history of acute rheumatic fever ten years ago and had been under observation for three to four years for mitral stenosis, developed rather suddenly, cough, wheezing, running of the nose, aches in the trunk, and fever. Despite massive doses of salicylates and tetracycline, the symptoms continued unabated, whilst œdema of the ankles, tender enlargement of liver, engorgement of the cervical veins, tachycardia, and postural dyspnœa developed during the second week of illness. Besides 
typically long, mid- and late-diastolic murmurs of mitral stenosis at the apex (observed on several occasions in the past in this patient), a new, harsh and long grade III systolic murmur, suggestive of mitral regurgitation now appeared. It was associated with slight outward displacement, of the apex thrust. A routine urine examination showed a light cloud of albumin and red cells, while a blood count showed 4.6 million red cells, 82 per cent $\mathrm{Hb}$., and 22,400 white cells with 72 per cent eosinophils. The patient was put on digitalis and diuretics and also hetrazan tablets, two thrice daily.

The electrocardiogram before treatment (Fig. 3), showed sinus tachycardia with intraventricular conduction defect, increased duration with notching and slurring of QRS complexes and depression of ST-T segments in leads I, II, and V4 to V6. After three days of treatment, the patient was afebrile and the dyspnœea

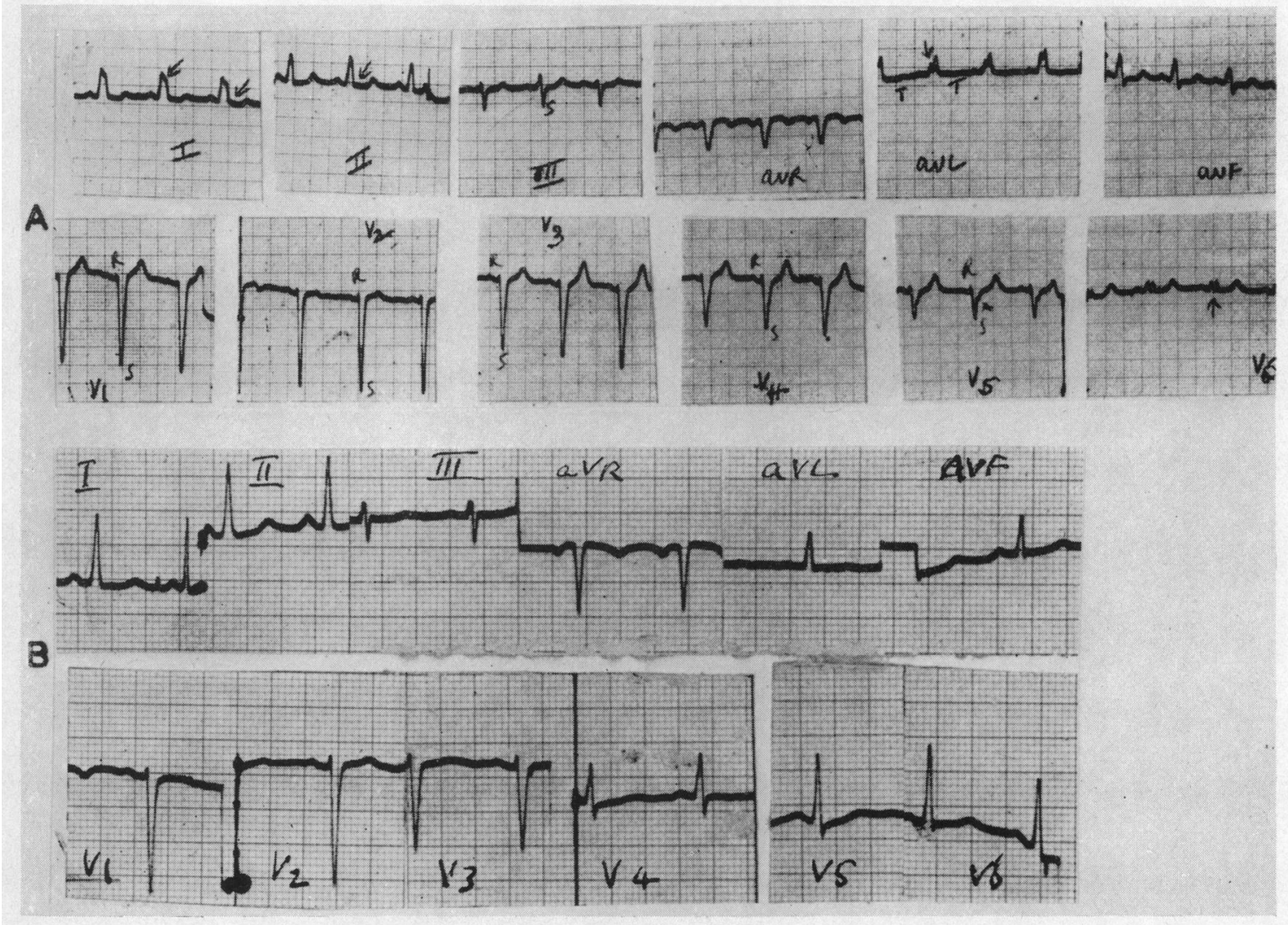

FIG. 3.-Case 3. Electrocardiogram before therapy, showing (A) sinus tachycardia, intraventricular conduction defect, notching of QRS, and S-T segment depression. (B) Electrocardiogram after therapy showing restoration towards normal three weeks later.

and cough had considerably improved. The white cell count after three weeks was 9000 with 18 per cent eosinophils, whilst a fresh electrocardiogram showed no evidence of the sinus tachycardia or intraventricular conduction defect, although lowering of the voltage of the $T$ waves in the $V$ leads was noted and thought to be digitalis effects.

The apical systolic murmur and the outward displacement of the apex had disappeared within six weeks of treatment being started.

Comment. The development of tropical eosinophilia in this patient with mitral stenosis was associated with a mild degree of cardiac enlargement, symptoms and signs of congestive cardiac failure and defective intraventricular conduction. Digitalis and diuretics exerted their expected beneficial effect but the control of tropical eosinophilia by hetrazan was judged to have been therapeutically important. 
Case 4. A 14-year-old school-boy, in good health except for occasional complaints of aches and pains in the calves after walking, developed sudden and severe cough, noisy breathing, malaise, backache, nocturnal paroxysmas of dyspnœa, and low-grade pyrexia. Within a few days of the onset of fever, he developed painful enlargement of the left knee, right ankle, and both shoulder joints with a pink flush over each joint. The deep cervical and right axillary lymph nodes were enlarged and tender, the liver and spleen were both just palpable, and small, tender subcutaneous nodules, undistinguishable from rheumatic nodules, were palpable over the right leg and both elbows. Examination of the throat showed congestion and follicular tonsillitis.

The urine and stools were normal. The temperature ranged between $98.6^{\circ}$ and $100^{\circ} \mathrm{F}$ and the blood count showed 19,400 white cells with 28 per cent eosinophils. The electrocardiogram (Fig. 4) showed sinus tachycardia, normal axis, increased height and duration of $\mathrm{P}$ waves, and mild $\mathrm{S}-\mathrm{T}$ segment depressions in leads V1 to V6.

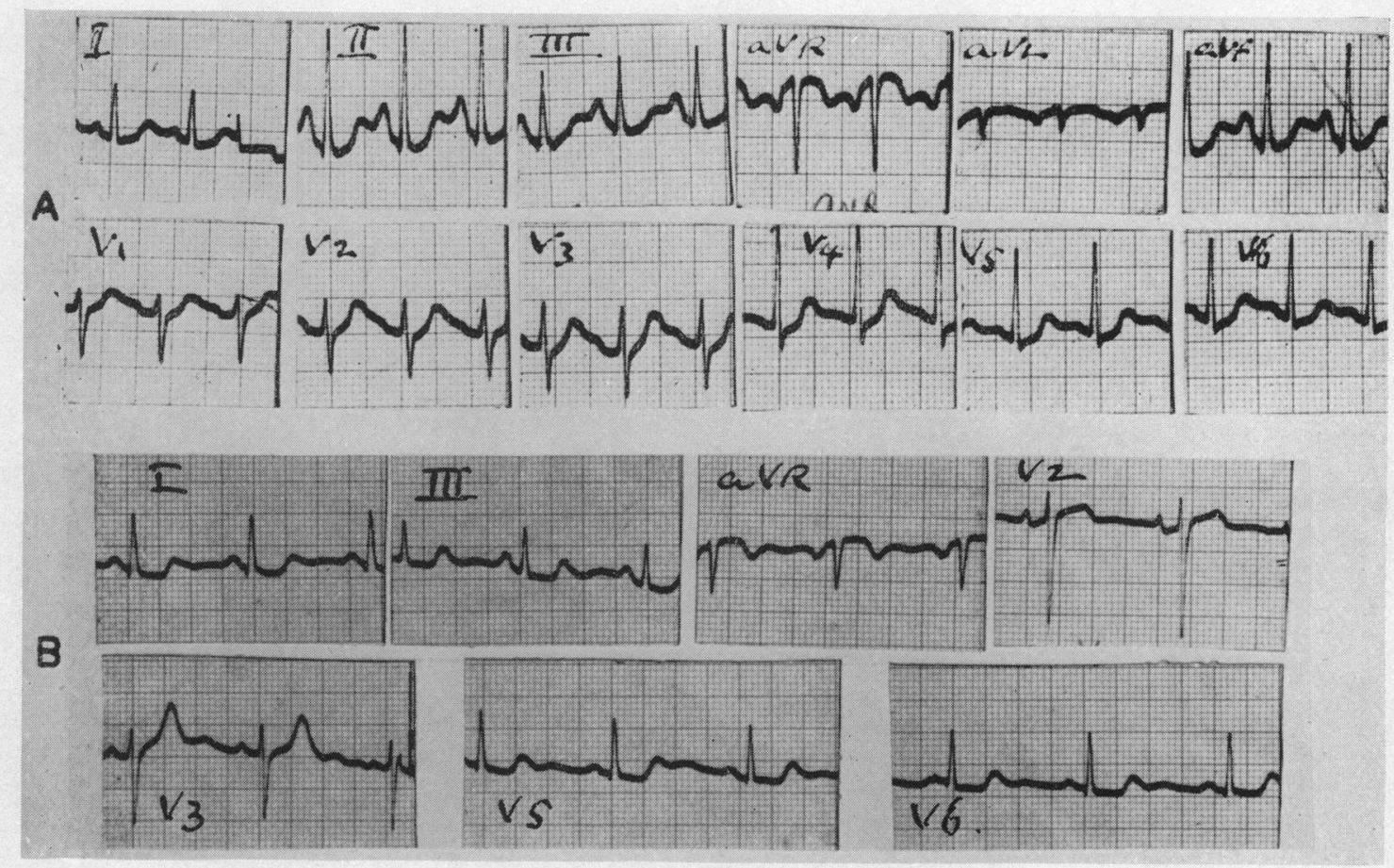

Fig. 4.-Case 4. Electrocardiograms showing (A) sinus tachycardia, increased voltage and duration of $P$ waves, and mild S-T segment depression; and (B) normal rate and regression towards normal patterns three weeks later.

The joint pains and swellings, lymphadenopathy, and fever subsided within four days of the first injection of acetylarsan intramuscularly. After three injections, at weekly intervals, the patient was cured, with an electrocardiogram almost normal and an eosinophil count of 4 per cent.

Comment. A syndrome, similar to that of rheumatic fever, with joint pains and swellings, rheumatic nodules, and fever, has been described previously in tropical eosinophilia. In this case, the syndrome was associated with minor electrocardiographic abnormalities, which disappeared as the illness came under control by treatment with a parenteral arsenical.

Case 5. A 46-year-old man complained of paroxysmal cough, nocturnal dyspnœa, wheezing, and low grade fever of about three weeks' duration. For several days, he had been experiencing sharp pain in the right mid-axillary region and back, particularly on deep breathing and cough. On examination, sonorous and sibilant rhonchi were heard on both sides of the chest; at the right base, the air entry appeared diminished and a scratching pleural rub was audible. Cardiac auscultation revealed a loud and split second sound in 
the pulmonary area and a grade I systolic murmur over the mitral and pulmonary areas. The white cell count was 18,600 per cu. mm. with 56 per cent eosinophils.

An electrocardiogram (Fig. 5) showed infrequent ventricular extrasystoles, sinus tachycardia, low voltage of P waves, and depression of S-T segments in leads I, II, and V2 to V6. Within two weeks of starting hetrazan, 2 tablets thrice daily, the patient was free of all symptoms, the clinical signs had disappeared and the cardiogram had become almost normal.

Comment. In addition to the signs of dry pleurisy, there were indications of cardiovascular involvement in this case of tropical eosinophilia as shown by non-specific ST-T abnormalities, low P waves, ventricular extrasystoles, and soft systolic murmur. The malady responded swiftly to treatment by hetrazan.

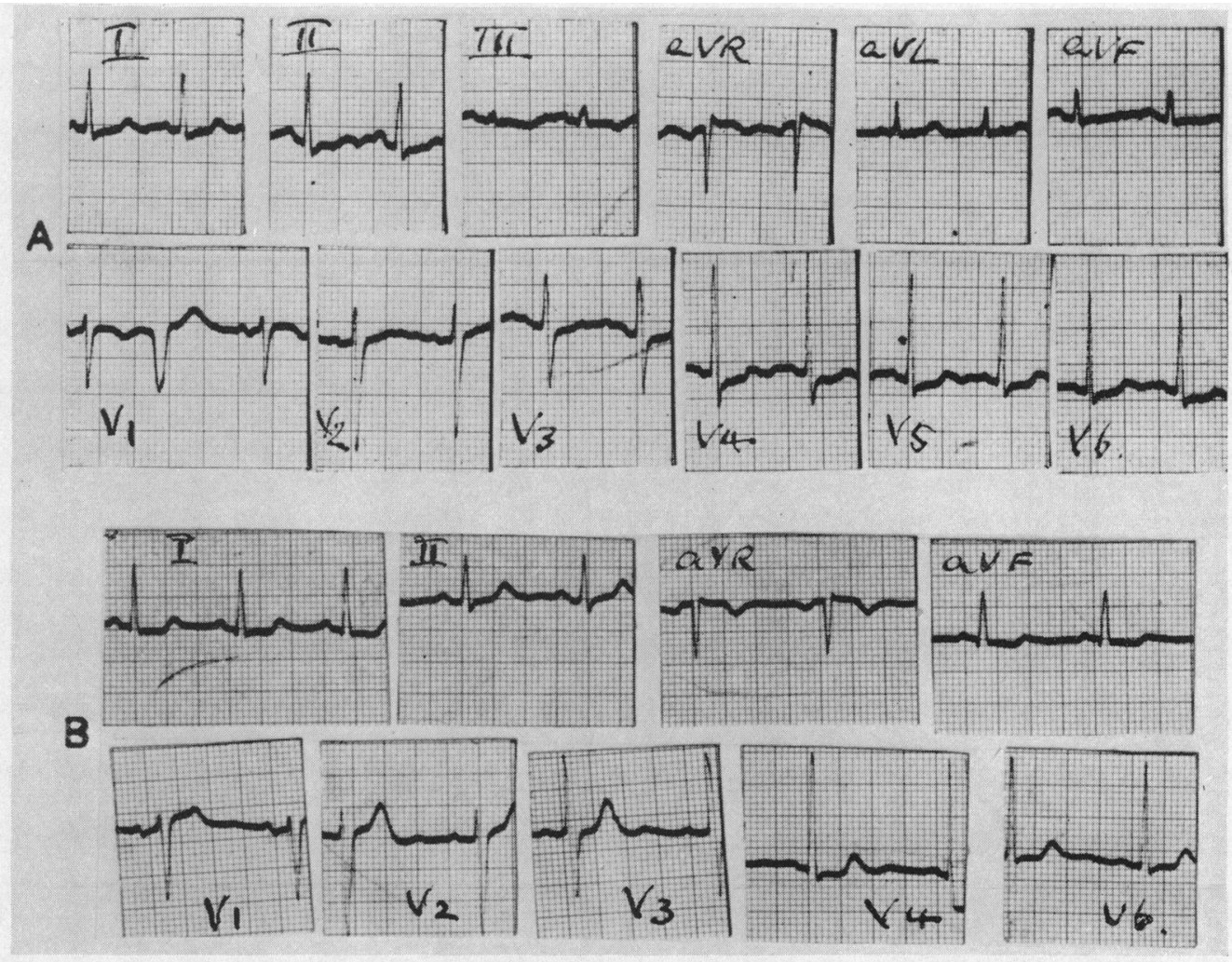

FIG. 5.-Case 5. Electrocardiograms showing (A) occasional ventricular extrasystoles, low voltage of $P$ waves, $\mathrm{S}-\mathrm{T}$ depression, and sinus tachycardia; and (B) normal heart rate and regression towards normal patterns a fortnight later.

Case 6. A 52-year-old business man who had been the subject of mild hypertension and diabetes of moderate degree for years, and who was continuously taking oral rauwolfia and tolbutamide for his ailments, was suddenly stricken with what appeared to be acute bronchitis; there was severe and unproductive cough, wheezing respiration, postural dyspnœa, and fever ranging between $99^{\circ}$ and $101^{\circ} \mathrm{F}$. In spite of antibiotics and symptomatic treatment, his condition continued to deteriorate, and he developed a mild degree of ankle odema with tender enlargement of the liver. The white cell count at the time of observation was 18,200 per cu. $\mathrm{mm}$. with 58 per cent eosinophils. Treatment was instituted with bed rest, digitalis, diuretics, and hetrazan, two tablets, four times a day. Within 16 hours of starting this therapy he had repeated attacks of anginal pain with left arm radiation and feelings of constriction. The pains were accompanied by a moderate rise of blood pressure and mild sweating and restlessness but no vomiting. The heart sounds were feeble, and a protodiastolic gallop rhythm was audible near the apex. Rhonchi were heard all over both sides of the chest and coarse and medium sized moist râles over both bases. 
An electrocardiogram taken between successive attacks of anginal pain showed left axis deviation with marked sagging of the S-T segments in leads II, III, aVF, and V2 to V6, and also inversion of T waves in leads I and aVL. This tracing strongly suggested an acute coronary insufficiency or subendocardial infarction.

Within a week of beginning treatment, the clinical condition of the patient had improved considerably, the anginal pain, cough, dyspnœa, œdema, and hepatomegaly all having disappeared. During the second week of convalescence, however, the patient had a more violent and continuous bout of chest pain with bilateral radiation into both shoulders and arms, profuse sweating, vomiting, and precipitous fall of blood pressure to 96/76. An electrocardiogram taken the day after showed the typical patterns of acute myocardial infarction. A white cell count at this stage showed a leucocytosis of 16,800 per cu. mm. with 68 per cent polymorphs and 8 per cent eosinophils. Despite anticoagulant therapy, sedatives, and peripheral stimulants, the patient's condition deteriorated rapidly and he succumbed with acute pulmonary œdema about 72 hours after the onset of severe chest pain. A necropsy was not permitted.

Comment. This case serves to emphasize the serious repercussions of a relatively benign ailment in a patient afflicted with arteriosclerotic heart disease and diabetes. At the height of an attack of tropical eosinophilia he suffered acute coronary insufficiency. Treatment benefited him for a few days but then he developed acute myocardial infarction and died three days later from pulmonary œdema.

\section{Discussion}

Apart from a few vague references to the subject of cardiovascular involvement in tropical eosinophilia, there are no well-controlled clinical or electrocardiographic studies or necropsy data to throw light on this important subject. As far back as 1921, Aubertin and Gerous reported a case of eosinophilia (60 to 70 per cent of total white cells) with cardiac failure and atherosclerosis of the pulmonary artery. Præcordial pain, simulating angina pectoris, has been reported by Jhatakia (1946) and Vishwanathan (1948). Of the atypical cases reported by D'Abrera (1958) one simulated rheumatic heart disease and another rheumatic fever with carditis. In a patient with tropical eosinophilia who had also mitral stenosis and congestive cardiac failure, described by Misra and Prakash (1957), necropsy failed to disclose any evidence of recent rheumatic infection.

The paucity of existing data on the subject of cardiovascular involvement in tropical eosinophilia is not surprising in view of the fact that tropical eosinophilia was unknown to the medical profession until a few years ago. Moreover, the short course and uneventful recovery in the majority of cases leave little or no scope for investigation of this small aspect of clinical medicine which has hitherto attracted little attention.

The cardiovascular manifestations of tropical eosinophilia, although mild and generally devoid of serious consequences, may however possess dangerous potentialities when the cardiovascular system is grossly damaged or impaired by pre-existing disease. The importance of such a possibility, not stressed sufficiently in the past, is borne out by the illustrative case reports presented here. The clinical and electrocardiographic abnormalities encountered in the present case histories serve to emphasize certain points of interest. The cardiovascular system is by no means as immune to the ravages of the disease as has been believed in the past. Cardiovascular involvement is particularly frequent and significant when specific treatment is delayed, usually through mis-diagnosis, or when pre-existing valvular or ischæmic disease renders the heart more vulnerable.

The electrocardiographic findings were of mild degree and non-specific, and did not suggest gross myocardial damage. In the absence of necropsies, the pathological basis of these abnormalities, whether secondary to pyrexia, right ventricular strain, anoxæmia, eosinophilic infiltration of the myocardium, or administration of drugs, must remain conjectural. Although cardiac consequences, when they occur, are usually mild they may at times pose problems in differential diagnosis, particularly from acute rheumatic fever, rheumatic carditis, valvular heart disease, congestive cardiac failure or pericarditis. Such difficulties have been reported previously by several authors, and they have been enountered on several occasions during the present investigation. 


\section{SUMMARY}

One hundred cases of tropical eosinophilia, proven hæmatologically, were studied from the standpoint of cardiovascular involvement. While præcordial pain occurred in one-fifth of all patients, in only three was the pain judged to be anginal. Systolic murmurs of varying intensity were heard in 7 patients, but always transiently. In 36 there was a loud pulmonary second sound, but indications of congestive heart failure were found in only 6 instances. Every patient except one, who died with transmural infarction, eventually recovered but in some dyspnœa persisted for many weeks.

Significant abnormalities in the electrocardiogram were recorded in 37 of the 100 patients studied. They were, with few exceptions, mild and transient. When cardiovascular disorders occurred they generally bore no relation to the degree or duration of fever or to the severity of respiratory involvement. They were observed mainly in those patients in whom specific therapy was delayed or in whom there was pre-existing heart disease.

\section{REFERENCES}

Aubertin, and Girous (1921). Quoted by Forkner (1938). Presse méd., 29, 314.

Bousser, J. (1957). Biologie et Pathologie (Paris), 28, 553.

Chaudhuri, R. M. (1956). Jour. Ind. med. Assoc., 27, 195.

D'Abrera, V. St. E. (1958). Med. J. Malaya, 12, 559.

Danaraj, T. J., Da Silva, L. S., and Schacher, J. F. (1957). Proc. Alumuni Ass. Malaya, 10, 109.

Frimont-Möller, C., and Barton, R. M. (1940). Ind. med. Gaz., 75, 607.

Gault, E. W., and Gebba, G. (1957). Lancet, $2,472$.

Jhatakia, K. U. (1946). Ind. med. Gaz., 81, 179.

Joseph, A. D. (1946). Ind. med. Gaz., 81, 515.

Loeffler, W. (1932). Beitr. Klin. Tuberk., 79, 368.

Meyers, F. M., and Kouwenaar, W. (1939). Genesk. Tijdschr. Nederl. Indie, 79, 835.

Misra, S. S., and Parakash, S. (1957). J. Postgrad. Med., 3, 162.

Van der Sar, A., and Hartz, H. (1945). Amer. J. Trop. Med., 25, 83.

Viswanathan, R. (1948). Quart. J. Med., 17, 257.

- (1947). Ind. med. Gaz., 82, 49.

Weingarten, R. J. (1943). Lancet, 1, 103. 